Discussion Paper 128

Institute for Empirical Macroeconomics

Federal Reserve Bank of Minneapolis

90 Hennepin Avenue

Minneapolis, Minnesota 55480-0291

February 1999

\title{
Private Money and Reserve Management in a Random-Matching Model
}

\author{
Ricardo de O. Cavalcanti \\ The Pennsylvania State University \\ and Getúlio Vargas Foundation \\ Andrés Erosa \\ The University of Western Ontario
}

Ted Temzelides

University of Iowa

\begin{abstract}
In this paper, we develop a model of money and reserve-holding banks. We allow for private liabilities to circulate as media of exchange in a random-matching framework. Some individuals, which we identify as banks, are endowed with a technology to issue private notes and to keep reserves with a clearinghouse. Bank liabilities are redeemed according to a stochastic process that depends on the endogenous trades. We find conditions under which note redemptions act as a force that is sufficient to stabilize note issue by the banking sector.

*We thank Nobu Kiyotaki, Narayana Kocherlakota, Robert Lucas, Neil Wallace, Warren Weber, Ruilin Zhou, and an anonymous referee for helpful comments. Part of this paper was completed while Cavalcanti was affiliated with the University of Miami and a visitor at the Federal Reserve Bank of Minneapolis, and while Temzelides was affiliated with the Federal Reserve Bank of Philadelphia. The views expressed herein are those of the authors and not necessarily those of the Federal Reserve Bank of Minneapolis or Philadelphia or the Federal Reserve System.
\end{abstract}




\section{Introduction}

An ongoing question in the field of money and banking is whether the private sector should be allowed to create money. One concern is what in a private monetary system can prevent too much money from being produced. In this paper, we study private note issue and address the old conjecture that note redemptions can discipline the amount of notes issued by the banking sector. In our model, money is essential in facilitating trade and banks issue redeemable liabilities by taking into account the probability of redemption. This probability, which depends on the behavior of the aggregate banking sector, influences each bank's decision to hold reserves. We find that a private monetary system may not only be stable but can also improve welfare when government currency is in sufficiently scarce supply.

We study private note issue and redemption by amending a model of money in which credit is otherwise nonexistent. Banking is made possible by the introduction of a clearinghouse, that is, a mechanism for note exchange, to a simple monetary model in the spirit of Kiyotaki and Wright (1989). The clearinghouse can be interpreted as a record-keeping technology that makes private money creation possible for a subset of the population, that is, the banks. Because other forms of credit, such as lender of last resort, are not available in the model, redemptions through the clearinghouse introduce a reserve management problem. Illiquid banks face the threat of dissolution if reserves are insufficient to meet redemptions.

Much of the recent development of central banking and banking legislation is a response to the view that private banks are inherently unstable. ${ }^{1}$ Although fixed prices in our model prevent any form of inflation, banks can, in principle, attempt to buy goods and services

\footnotetext{
${ }^{1}$ See Friedman (1959). See also Fischer (1986), and references therein, for a discussion centered on Hayek's proposals on private money.
} 
with a costless paper currency that they can issue in unlimited amounts. However, early proponents of free banking have argued that a note exchange may reflux private notes at a speed that is sufficient to prevent overissue, which is a view known as "law of reflux." ${ }^{2}$ Indeed, our findings suggest that as long as banks find it difficult to borrow at short notice, the "law of reflux" can be a sufficient force to guarantee monetary stability. More specifically, we show that the aggregate quantity of private money remains limited when banking is relatively profitable.

The literature on reserve-holding banks is voluminous. Edgeworth (1888) was the first to offer a theory of money supply based on expectations about the stochastic behavior of banks' assets and liabilities. However, existing models of reserve inventory optimization are not monetary models in that there is no influence of inventory behavior on the equilibrium value of money or aggregate activity. ${ }^{3}$ Sargent and Wallace (1982) addressed the welfare role of private liabilities in an overlapping generations model of money, but without reserveholding banks. In contrast to previous work, our model provides a framework in which both money and banking have a welfare improving role.

The rest of the paper is organized as follows. Section II presents the model. Section III contains a discussion of welfare, followed by a short interpretive reference to some historic episodes.

\footnotetext{
${ }^{2}$ The speed of redemptions in a private system is considered pivotal to the free banking school of thought. The origins of the "law of reflux" may be traced to the real bills doctrine of Adam Smith and earlier writers. See Schwartz (1992), White (1984), and references therein.

${ }^{3}$ Phillips (1920) modeled money creation by imposing fixed reserve/liability ratios. Orr and Mellon (1961), among others, returned to Edgeworth by considering the decision theory that Arrow, Karlin, and Scarf (1958) formulated for business inventories. Tobin (1963) introduced an exogenous demand for money to the Phillips's structure in an attempt to reach general-equilibrium implications. For more recent attempts of addressing the private provision of liquidity, but without modeling money explicitly, see Holmström and Tirole (1998) and references therein.
} 


\section{The Model}

For ease of exposition, we first present a version of the model with a fixed currency supply and no private money. Next, banks and private money are introduced. The section is completed with a discussion of the banks' reserve management problem and of monetary stability.

\section{A. Government Currency}

Here we present the key elements allowing for fiat money to circulate as a medium of exchange. The environment in this subsection is closely related to the one in Kiyotaki and Wright (1989). Because we are not interested in commodity money, we assume that consumption goods are perishable; thus, only fiat money can circulate. Another difference is that we will assume that money is initially created exogenously and deterministically through the arrival of newborn agents.

Time is discrete and the horizon is infinite. Individuals face an exponential lifetime. (This assumption will prove useful in the next subsection, where it serves as a device allowing for the entry of banks in the economy.) A large number, formally a continuum, of individuals inhabit the economy. An individual may die at the end of each period with probability $\delta \in(0,1)$. In that event, the individual who dies is replaced in the next period by a newcomer with identical characteristics. We normalize the population size to be of measure one, so that a measure $\delta$ of newborns enter the economy in every period.

There is a finite number, $k \geq 3$, of types of consumption goods and individuals. All consumption goods are perishable and indivisible. Agents specialize in consumption and production of goods in a symmetric fashion. At the beginning of each period, there is a $\left[0, \frac{1}{k}\right]$ continuum of each type. Individuals of type $i$ can only consume good $i$ and produce good 
$i+1$ (modulo $k$ ). The instantaneous utility derived from consumption is $u>0$. Production requires no input except for efforts linked to disutility $e>0$, with $u>e$. All individuals maximize expected discounted utility, and the time discount factor is $\tilde{\beta}$. The effective discount factor, after death rates are taken into account, is $\beta=(1-\delta) \tilde{\beta} \in(0,1)$. Consumption and production take place once in a given period when two people meet. In every period, each individual is paired with another at random. The characteristics of the trading partners are drawn uniformly from the relevant population. Because $k \geq 3$, there is no double coincidence of wants.

We assume that a fraction $\mu_{c}$ of the newborns start their lives each with one unit of indivisible currency, interpreted as government fiat money. We impose an upper bound on money holdings. Individuals can hold at most one unit of currency (or, later, a private bank note). This implies that in meetings where there is trade, one unit of money is exchanged for one unit of good, that is, prices are exogenous. There is no enforcement technology, and individual trading histories are private information. This precludes any form of credit in this economy. Money is, therefore, essential since only bilateral trade of money for goods can prevent autarky.

Trade is possible when money holders meet with a producer of their consumption good that does not hold money. The producer can randomize, accepting with probability $\alpha \in[0,1]$, the exchange of a unit of his or her produced good for a unit of money. We denote the expected discounted lifetime utility for individuals holding one and zero units of money at the beginning of a period by $s_{1}$ and $s_{0}$, respectively. Trade takes place when $\beta\left(s_{1}-s_{0}\right)>e$, that is, when the value of acquiring money exceeds the disutility from production. The measure of individuals without money in each population type is denoted by $\tilde{p}$. Similarly, the 
measure of individuals with one unit of money in each population type is $q$ so that $\tilde{p}+q=\frac{1}{k}$. The Bellman equations are

$$
s_{1}=p\left(u+\beta s_{0}\right)+(1-p) \beta s_{1}
$$

and

$$
s_{0}=q \max _{\alpha}\left[\alpha\left(-e+\beta s_{1}\right)+(1-\alpha) \beta s_{0}\right]+(1-q) \beta s_{0}
$$

where $p=\alpha \tilde{p}$ is the measure per type that is willing to accept money. The law of motion across states is described as follows. At the beginning of a period, the measure per type starting with money is $q$. Each individual, with probability $\tilde{p}$, meets with a producer of the desired consumption good and with no money, who in turn accepts money with probability $\alpha$. As money changes hands, a measure of agents, $\alpha \tilde{p} q$, will switch to zero money holdings, and an equal measure acquires money. At the end of the period, $\delta q$ money holders per type die, while $\delta \frac{\mu_{c}}{k}$ money holders per type are born. The measure of money holders per type at the beginning of the next period, $q^{\prime}$, is thus given by

$$
q^{\prime}=q-\alpha \tilde{p} q+\alpha \tilde{p} q-\delta q+\delta \frac{\mu_{c}}{k}
$$

In a steady state, $q^{\prime}=q=\frac{\mu_{c}}{k}$ and $\tilde{p}=\frac{1-\mu_{c}}{k}$. In our notation, we impose a symmetric behavior across types, and we restrict our attention to symmetric steady states throughout the paper. We use bold letters, such as s, as a short representation of the corresponding list of variables indexed by states, such as $\left(s_{0}, s_{1}\right)$.

Definition 1. A monetary steady-state equilibrium for the economy without banking is an array (s, $p, q)$ satisfying the Bellman equations (1) and (2) and is such that $\alpha=1$ attains the 
maximum in (2), while $p=\frac{1-\mu_{c}}{k}$ and $q=\frac{\mu_{c}}{k}$.

In order to demonstrate the existence of a monetary steady-state equilibrium for this economy, we first restrict behavior by imposing $\alpha=1$ and then show that this constraint is nonbinding. This constraint, together with (1) and (2), yields

$$
(1-\beta(1-p-q))\left(s_{1}-s_{0}\right)=p u+q e,
$$

and the constraint is nonbinding when $\beta\left(s_{1}-s_{0}\right)>e$ for the $p$ and $q$ of the steady-state definition. Using (4), we can write this condition as

$$
p=\frac{1-\mu_{c}}{k}>\left(\frac{1}{\beta}-1\right)\left(\frac{1}{u / e-1}\right) .
$$

The above expression suggests that the value of acquiring money is higher when money is relatively scarce, that is, when $\mu_{c}$ is low, and when agents are sufficiently patient. We have shown the following.

Proposition 1. If $\beta$ is sufficiently close to one, there exists a monetary steady-state equilibrium for the economy without banking.

\section{B. Private Money}

We now introduce a record-keeping technology, which we call a clearinghouse or note exchange. Member banks can deposit reserves with the clearinghouse by recording the acceptance of money in trade meetings. In addition to the fraction $\mu_{c}$ per type of newborn individuals starting with currency, there is now a fraction $\mu_{b}$ starting with clearinghouse 
membership privileges. We will refer to these individuals as banks, and to the nonmembers as nonbanks. Banks are identical to nonbanks regarding all the physical elements so far presented. In particular, the measure of newborn banks is symmetrically divided into $k$ types, with bank type $i$ consuming good $i$ and producing good $i+1$ (modulo $k$ ).

Banks can, however, issue their own personal currencies - bank notes - in indivisible amounts (one at a time) and at no cost. The clearinghouse keeps a reserve balance for each member. When bank $A$ produces a good for somebody in a bilateral meeting in exchange for money, the balance of $A$ is credited by one unit. The "deposited" money is subsequently destroyed. If the money deposited as reserves is a note issued by bank $B$, then, in addition, the balance of $B$ is debited by one unit. This process corresponds to note redemption.

Membership to the clearinghouse is assumed to be conditional on the ability to meet redemptions. If the volume of a bank's notes redeemed exceeds its reserve balance at any point in time, the membership is terminated. This corresponds to bank dissolution. After dissolution, the former member continues his or her life as a nonbank, that is, as an individual without note issuing or note record-keeping privileges. Because a note can circulate among nonbanks for a long time, the assumed dissolution rule corresponds to regulation that is much weaker than $100 \%$ reserve requirements. Other minimum balances could be considered, but for the purposes of this paper, the cutoff line of zero balances is taken as a normalization.

Next we address the question of how the amount of new notes issued by banks depends on the profitability of the banking sector. By profitability, we mean the extra utility, or seigniorage, that banks can derive relative to nonbanks from the possible "float" of their notes. This "float" is possible since, in general, there will be a lag between the period when the bank enjoys consumption by issuing a new note and the period when the note is redeemed 
by the clearinghouse. Thus, banks are guaranteed a higher frequency of consumption than nonbanks. Therefore, the higher the time-discount rates, the higher the expected discounted utility of banks relative to nonbanks.

We assume no further penalties for banks that reach negative reserves other than the loss of banking privileges. We actually find it convenient to assume that closed banks are given a unit of currency immediately after dissolution. Thus, in the worst-case scenario of a high volume of redemptions followed by dissolution, banks restart life in the best possible state for nonbanks. Independently of their level of reserves or notes in circulation, banks will, therefore, choose to deposit with the clearinghouse any monetary proceeds from trade meetings.

The fact that banks always deposit monetary proceeds as reserves turns the upper bound on money holdings into a nonbinding constraint for banks, although it is binding for nonbanks. This asymmetry originates from the treatment of reserves as a gathering of information about past trades, which entails a credit arrangement for banks that is not available to nonbanks. ${ }^{4}$ Hence, in addition to the advantages from seigniorage, banks are in a sense exempt from the holding requirements that others are subject to.

\section{Reserve Management}

In our model, an individual bank is concerned about the decisions by other banks to accumulate reserves. For an individual bank, an increased redemption rate would tend to reduce the float of his or her own notes and would require the (costly) buildup of additional reserves

\footnotetext{
${ }^{4}$ We are implicitly making the assumption that society has the capability of acquiring information about a measure of banks and cannot monitor nonbanks. This informational view of the note exchange formally requires that notes be dated with the time of issue. For ease of exposition, we shall, however, make specific assumptions about the redemption process that dispenses with dating notes in our notation.
} 
in order to avoid dissolution. The "law of reflux" thus comes from an externality present in the aggregation of the banking sector and goes beyond the exogenous demand for reserves emphasized by Edgeworth (1888). ${ }^{5}$

For simplicity, we assume that the clearinghouse redeems notes held by nonbanks who die and that notes issued by members in good standing who later fail or die are still honored. As a result of the first assumption, a bank always knows the volume of his or her notes in circulation after redemptions occur. As a result of the second assumption, note holders face no risk of default, and the market value of notes issued by dissolved or dead banks is preserved since the notes count as valid reserves. Thus, note holders do not have to care about the identity of the issuer. These assumptions allow us to restrict our attention to the case where all notes in circulation are equally valuable. ${ }^{6}$

We further assume that the banking status of any participant in a trade meeting is private information and will ignore the possibility of money-for-money exchanges. The former restriction implies that banks issuing notes in order to consume, not knowing whether their trading partners are also banks, face the risk that their notes are redeemed immediately. These assumptions are made for ease of exposition and are not essential for our results.

We can now represent the maximization problem of nonbanks by the same Bellman equations (1) and (2) that are derived in the previous case when all money creation is assumed to be exogenous. We now interpret $s_{1}$ to be the expected discounted value of a nonbank with one unit of money (currency or note). The value of a nonbank without money is still denoted by $s_{0}$. Figure 1 presents the sequence of events at period $t$.

\footnotetext{
${ }^{5}$ There is no free entry in our model since the measure of entrants in the banking sector is exogenous.

${ }^{6}$ The lack of default risk on notes is largely a simplifying assumption. By ruling out reputation effects, we can concentrate on the role of the reflux principle alone in disciplining note issue by banks.
} 


$$
\begin{aligned}
t \rightarrow & v_{r, m} \rightarrow \text { trade meetings and reserve deposits } \rightarrow \text { births } \\
& \text { and deaths } \rightarrow w_{r^{\prime}, m^{\prime}, j} \rightarrow \text { balance adjustments } \rightarrow t+1
\end{aligned}
$$

\section{Figure 1: Sequence of Events}

Consider a bank with reserve balance $r$ and with quantity $m$ of his or her previously issued notes still in circulation. At the beginning of the period, the state for the bank is $(r, m)$, and his or her expected discounted utility is $v_{r, m}$. If the bank trades during a period, the trade is either an opportunity to issue a new note or to deposit a unit of currency or note with the clearinghouse. Then death or survival occurs. If the bank issues a new note and the recipient is also a bank, the fact that the new note is deposited and does not enter circulation is marked by adding to the state the indicator $j=0\left(\left(r^{\prime}, m^{\prime}, j\right)=(r-1, m, 0)\right)$. If the new note enters circulation because it has been issued to a nonbank who survives, we have that $j=1\left(\left(r^{\prime}, m^{\prime}, j\right)=(r, m+1,0)\right)$. The term $w_{r, m, j}$ denotes a bank agent's expected discounted value in state $(r, m, j)$ after trade but before the uncertainty about the float of his or her old notes is revealed. The new reserve balances are calculated by the clearinghouse at the end of each period and depend on the economywide trades. From its new balance, each bank can infer the new amount of its notes that remain in circulation. A newborn bank is assumed to enter into the economy with $(r, m)=(0,0)$.

Because notes are treated indistinguishably by the nonbank public, the probability that a note in circulation gets redeemed is invariant to the issuer's identity. We let $\pi$ denote this probability, which is endogenous in our model. For $i \leq m$, a bank that is in state 
$(r, m, j)$ just before deposits are cleared faces the probability $\left(\begin{array}{c}m-j \\ i\end{array}\right) \pi^{i}(1-\pi)^{m-i-j}$ that $i$ of his or her old notes $(m-j$ in total $)$ are redeemed. Taking into account that the bank switches to expected discounted utility $s_{1}$ if a negative reserve balance attains, we find that the relationship among the current $\mathbf{w}$ and the next period's $\mathbf{v}$ is given by

$$
\begin{aligned}
w_{r, m, j}= & \beta \sum_{0 \leq i \leq m}\left(\begin{array}{c}
m-j \\
i
\end{array}\right) \pi^{i}(1-\pi)^{m-i-j} v_{r-i, m-i} \\
& +\beta \sum_{r<i \leq m}\left(\begin{array}{c}
m-j \\
i
\end{array}\right) \pi^{i}(1-\pi)^{m-i-j} s_{1} .
\end{aligned}
$$

At the time of trade meetings, an individual bank in state $(r, m)$ chooses whether to improve his or her reserves by accepting money in exchange for production with probability $\gamma_{r, m} \in[0,1]$. Nonbanks will always agree to exchange their money holdings for consumption. However, a concern about their level of reserves may induce banks to behave differently when deciding whether to issue a note in exchange for consumption. We let $\phi_{r, m} \in[0,1]$ denote the probability that a bank in state $(r, m)$ issues a note. As before, we let $p$ denote the fraction of the population per type that is willing to produce goods in exchange for money, and let $q$ denote that fraction that is willing to pay money for consumption. Hence, $\mathbf{v}$ and $\mathbf{w}$ are related to $\gamma$ and $\phi$ according to

$$
\begin{aligned}
v_{r, m}= & q \max _{\gamma_{r, m}}\left[\gamma_{r, m}\left(-e+w_{r+1, m, 0}\right)+\left(1-\gamma_{r, m}\right) w_{r, m, 0}\right]+ \\
& p \max _{\phi_{d, m}}\left\{\phi_{r, m}\left[u+d w_{r, m+1,1}+(1-d) w_{r-1, m, 0}\right]+\left(1-\phi_{r, m}\right) w_{r, m, 0}\right\}+ \\
& (1-p-q) w_{r, m, 0}
\end{aligned}
$$

where $d$ is the probability that a new note enters circulation because it is issued to a nonbank 
who survives.

The law of motion for the distribution of agents across states is more complex now than in the case without banks. We let $y_{0}$ denote the steady-state measure per type of nonbanks without money at the beginning of a period, and $y_{1}$ is the measure of nonbanks with money, be it currency or note. We let $x_{r, m}$ denote the steady-state measure per type of banks in state $(r, m)$ at the beginning of a period. In addition, we let $z$ denote the measure of banks that suffer dissolution at the end of a period. We let $T_{\alpha, \gamma, \phi}$ denote the continuous mapping implied by the strategies $\alpha, \gamma$, and $\boldsymbol{\phi}$. The function $T_{\alpha, \gamma, \phi}$ maps $(\mathbf{x}, \mathbf{y}, z)$ into the next period's distribution. We formally describe this mapping in the Appendix. In what follows, we let $\boldsymbol{\gamma} \mathbf{x}$ and $\boldsymbol{\phi} \mathbf{x}$ denote the inner products $\sum_{r, m} \gamma_{r, m} x_{r, m}$ and $\sum_{r, m} \phi_{r, m} x_{r, m}$, respectively. We next define a symmetric steady state according to whether notes circulate among nonbanks.

Definition 2. A monetary steady-state equilibrium with banking is an array $(\mathbf{s}, \mathbf{v}, \mathbf{w}, \boldsymbol{\gamma}, \boldsymbol{\phi}, p$, $q, \mathbf{x}, \mathbf{y}, z)$ satisfying the Bellman equations (1), (2), (6), and (7), such that $\alpha=1$ attains the maximum in (2); $(\boldsymbol{\gamma}, \boldsymbol{\phi})$ attains the maximum in $(\mathbf{7}) ;(\mathbf{x}, \mathbf{y}, z)=T_{\alpha, \gamma, \phi}(\mathbf{x}, \mathbf{y}, z)$ (distributions remain constant); and $p=y_{0}+\boldsymbol{\gamma} \mathbf{x}, q=y_{1}+\boldsymbol{\phi} \mathbf{x}, \pi=\delta+(1-\delta) \boldsymbol{\gamma} \mathbf{x}, d=(1-\delta) y_{0} / p$, and $z \leq \delta \mu_{b}$ (dissolution and entry rates are compatible).

The last three requirements deserve some discussion. A note held by a nonbank is always redeemed upon death. It is also redeemed when the nonbank is able to trade it in a meeting with a bank producer, and the nonbank survives, an event occurring with probability $(1-\delta) \boldsymbol{\gamma} \mathbf{x}$. We thus require that in a steady state, $\pi=\delta+(1-\delta) \boldsymbol{\gamma} \mathbf{x}$. The probability that a new note is issued to a nonbank who survives (probability $(1-\delta) y_{0}$ ), conditional that money is accepted in trade (probability $p$ ), is thus $d=(1-\delta) y_{0} / p$. Finally, recall that $z$ is the 
measure of banks exiting the sector in a steady state, while $\delta \mu_{b}$ is the measure of newborn banks. Thus, unless $z \leq \delta \mu_{b}$, the last requirement in the definition, the outflow of banks cannot be met by an equivalent inflow of newborns into the banking sector.

\section{Monetary Stability}

In this section, we study the question of whether the clearinghouse redemption mechanism is sufficient to create a self-disciplining banking sector. Our restrictions of production, money holdings, and trade anonymity imply that goods either exchange for money at fixed prices or do not exchange at all. The introduction of banking cannot, therefore, create a steady state with inflation in our model. However, the question of whether monetary stability is obtained can be formulated as the question of whether a monetary steady-state equilibrium in which banks issue notes exists.

Our equilibrium definition does not rule out the possibility of some bank failures $(z>0)$. Banks taking advantage of the seigniorage opportunities in our model are typically illiquid, and there is, therefore, at least a small probability of excess redemptions, followed by dissolution. The question is, thus, whether banks have the proper incentives to build reserves and to limit note issue at levels that induce nonbanks to accept their intrinsically-useless pieces of paper. We show below that private banks will limit their note issue in economies where the rate of discounting is small. In particular, it follows that the steady-state value of the dissolution rate due to excessive note issue, $z$, is driven to zero as $\beta$ approaches unity.

Our argument on the existence of a monetary equilibrium with banking proceeds by appealing to a fixed-point argument used in Aiyagari and Wallace (1991). ${ }^{7}$ We proceed by

\footnotetext{
${ }^{7}$ Aiyagari and Wallace (1991) restrict the set of strategies under constraints that imply positive consump-
} 
first restricting nonbanks to always accept money $(\alpha=1)$. Next we restrict banks to back note issue by $100 \%$ reserves on a range of the state space indexed by a constant $R$. Banks in this range are also restricted to accept money in trade meetings. The restrictions for banks read $\gamma_{r, r}=1$ and $\phi_{r, r}=0$ for $r \leq R$. Nonrestricted banks enjoy seigniorage until the minimum reserve balance $R$ is reached. Because every newborn bank starts in state $(r, m)=(0,0)$, $R$ can be chosen sufficiently large so that $(\mathbf{x}, \mathbf{y}, z)=T_{\alpha, \gamma, \phi}(\mathbf{x}, \mathbf{y}, z)$ implies $z<\delta \mu_{b}$ for any $(\alpha, \gamma, \phi)$ satisfying our restrictions. In other words, we can bound from above the measure of dissolutions, $z$, so that it conforms with the monetary steady-state definition by controlling, through the choice of $R$, the mass of banks that follow $100 \%$ reserve requirements.

Then we proceed by constructing a correspondence, $\psi$, as follows. Given $(\mathbf{s}, \mathbf{v}, \mathbf{w}, \boldsymbol{\gamma}, \boldsymbol{\phi}$, $\mathbf{x}, \mathbf{y}, z)$, we determine $p, q, \pi$, and $d$ from the steady-state definition and $(\mathbf{s}, \mathbf{v}, \mathbf{w})$ as the right side of (1), (2), (6) and (7). In addition, we determine $(\boldsymbol{\gamma}, \boldsymbol{\phi})$ according to the above restrictions for $r \leq R$ and as the correspondence of dominant strategies that attains the maximum in (7) for $r>R$. Finally, the new measures over states are given by $T_{\alpha, \gamma, \phi}(\mathbf{x}, \mathbf{y}, z)$. The existence of a restricted monetary steady state then follows since $\psi$ satisfies the conditions of Kakutani's fixed-point theorem. ${ }^{8}$

The last step is to argue that the restrictions are nonbinding when $\beta$ is sufficiently large. Regarding nonbanks, a sufficient condition to that effect follows from the same argument employed in the previous case with no private money. To an individual nonbank, the fact

tion, and then they proceed by constructing a correspondence mapping the product of the spaces of expected discounted values, strategies, and distributions into itself. They show that this correspondence has a fixed point, which they call a restricted steady state. Finally, they find sufficient conditions on parameters guaranteeing that the initially imposed constraints are not binding. When parameters satisfy such conditions, the fixed point is actually an (unrestricted) steady state with positive consumption.

${ }^{8}$ We assume an upper bound $(K, K)$ on the state space for banks so that this space becomes compact. Because $\delta>0$, the measure of banks who survive until they reach a state outside this upper bound can be made arbitrarily small by the choice of a sufficiently large $K$. Hence, this compactness restriction is innocuous. 
that other nonbanks without money, as well as newborn banks, are willing to accept money with probability one implies a lower bound on $p$. Thus, if $\beta$ is sufficiently high so that the inequality in (5) holds, the constraint $\alpha=1$ is nonbinding.

We can also manipulate equations (1), (2), (6), and (7) to show that for $\beta$ sufficiently large, the restrictions for banks are also nonbinding. Notice that if $\phi_{r, r}=0$ is nonbinding for $r \leq R$, then $\gamma_{r, r}=1$ is also nonbinding for $r \leq R$; otherwise, banks would be choosing a form of autarky after reaching a level of reserves $r \leq R$, which is clearly suboptimal. We now show that $\phi_{r, r}=0$ is nonbinding for $r \leq R$. It suffices to show that $v_{0,0}-s_{1}$ can be made arbitrarily large by picking $\beta$ sufficiently close to one in a restricted steady state. By issuing a note at state $(r, r)$, a bank faces, with positive probability, the possibility of losing $v_{0,0}-s_{1}$ or more in the event of excess redemptions. Next we show that this cost outweighs the short-run gain of issuing an additional note, $u$. Formally, equation (7) implies that $\phi_{r, r}=0$ if $u+d w_{r, r, 1}+(1-d) w_{r-1, r, 0}<w_{r, r, 0}$. Since $w_{r, r, 1}<w_{r, r, 0}$, this inequality is true if $u<(1-d)\left(w_{r, r, 0}-w_{r-1, r, 0}\right)$. From (6), we have that

$$
w_{r, r, 0}-w_{r-1, r, 0}=\beta \sum_{i=0}^{r-1}\left(\begin{array}{c}
r \\
i
\end{array}\right) \pi^{i}(1-\pi)^{r-i}\left(v_{r-i, r-i}-v_{r-1-i, r-i}\right)+\beta \pi^{r}\left(v_{0,0}-s_{1}\right)
$$

The above expression is bounded below by $\beta \pi^{r}\left(v_{0,0}-s_{1}\right)$. Thus, $\phi_{r, r}=0$ if $u<$ $(1-d) \beta \pi^{r}\left(v_{0,0}-s_{1}\right)$ for all $r \leq R$. Since $1-d>\delta$ and $\pi^{r} \geq \delta^{r}>0$, the conclusion follows if $v_{0,0}-s_{1}$ is sufficiently large.

We now establish that $v_{0,0}-s_{1} \rightarrow \infty$ as $\beta \rightarrow 1$. The value functions that solve (6) and (7) are increasing in $d$, the probability that a new note enters circulation. We proceed by showing that solutions to (6) and (7) satisfy the above limit even when banks are deprived of 
seigniorage. (All notes are redeemed instantly.) Even in that extreme case, the banks' larger inventory capability allows them to consume goods more frequently than nonbanks. Let us denote by $\tilde{v}_{i}$ the expected discounted utility for a bank with $i$ reserves that is attained by the policy of backing every note issued. Because we are working with the worst-case scenario that $d=0$, no note enters in circulation, and $m=0$ and $r=i$. The counterparts of (6) and (7) for $\tilde{v}_{0}$ and $\tilde{v}_{1}$ are

$$
\tilde{v}_{0}=\beta \tilde{v}_{0}+q\left[-e+\beta\left(\tilde{v}_{1}-\tilde{v}_{0}\right)\right]
$$

and

$$
\tilde{v}_{1}=\beta \tilde{v}_{1}+p\left[u+\beta\left(\tilde{v}_{0}-\tilde{v}_{1}\right)\right]+q\left[-e+\beta\left(\tilde{v}_{2}-\tilde{v}_{1}\right)\right] .
$$

In a restricted steady state, $p$ and $q$ are bounded away from zero for any $\beta \in(0,1)$. As is typical in this class of models, $\tilde{v}_{0} \rightarrow\left(\tilde{v}_{1}-e\right)$ as $\beta \rightarrow 1$, so it suffices for our purposes to show that $\tilde{v}_{1}-s_{1} \rightarrow \infty$ as $\beta \rightarrow 1$. We derive a lower bound for $\tilde{v}_{2}$ according to

$$
(1-\beta) \tilde{v}_{2}=p\left[u+\beta\left(\tilde{v}_{1}-\tilde{v}_{2}\right)\right]+q \max \left\{0,-e+\beta\left(\tilde{v}_{3}-\tilde{v}_{2}\right)\right\} \geq p\left[u+\beta\left(\tilde{v}_{1}-\tilde{v}_{2}\right)\right] .
$$

Since $(1-\beta) \tilde{v}_{1}=p\left[u+\beta\left(\tilde{v}_{0}-\tilde{v}_{1}\right)\right]+q\left[-e+\beta\left(\tilde{v}_{2}-\tilde{v}_{1}\right)\right]$, we can work with $\tilde{v}_{2}-\tilde{v}_{1}$ in order to obtain the inequality $[1-\beta(1-p-q)]\left(\tilde{v}_{2}-\tilde{v}_{1}\right) \geq q e+p \beta\left(\tilde{v}_{1}-\tilde{v}_{0}\right)$. Now (9) implies that $[1-\beta(1-p-q)](1-\beta) \tilde{v}_{1} \geq(1-\beta(1-p-q)) p u-(1-\beta(1-p)) q e+(1-\beta(1-p)) p \beta\left(\tilde{v}_{0}-\tilde{v}_{1}\right)$, or, if we rearrange terms,

$$
\begin{aligned}
{[1-\beta(1-p-q)](1-\beta) \tilde{v}_{1} \geq } & (1-\beta)(p u-q e)+p^{2} \beta u+ \\
& p q \beta(u-e)+(1-\beta(1-p)) p \beta\left(\tilde{v}_{0}-\tilde{v}_{1}\right) .
\end{aligned}
$$


Similarly, expressions for $s_{0}, s_{1}$, and $s_{1}-s_{0}$ promptly imply

$$
[1-\beta(1-p-q)](1-\beta) s_{1}=(1-\beta) p u+p q \beta(u-e)
$$

Because $\tilde{v}_{1}-\tilde{v}_{0} \rightarrow e$ as $\beta \rightarrow 1$, we can use (10) and (11) to conclude that

$$
\lim _{\beta \rightarrow 1}\left\{[1-\beta(1-p-q)](1-\beta)\left(\tilde{v}_{1}-s_{1}\right)\right\} \geq \lim _{\beta \rightarrow 1}\left\{p^{2} \beta(u-e)-(1-\beta) q e\right\} .
$$

Since $u>e$ and $p$ is bounded away from zero, it follows that the right-side limit is strictly positive. Since the term $(1-\beta)$ on the left side converges to zero, we may conclude that $\tilde{v}_{1}-s_{1} \rightarrow \infty$ as $\beta \rightarrow 1$. We have proved the following.

Proposition 2. If $\beta$ is sufficiently close to one, there exists a monetary steady state for the economy with banking.

\section{Welfare and Other Remarks}

In this section, we comment on the welfare role of private notes. We find that private bank notes improve welfare when government currency is sufficiently scarce. ${ }^{9}$ As we discuss below, some historic episodes provide evidence of such a role. Monetary stability was often attained when private banks were permitted to grow sufficiently large so as to handle well their redemption processes, as predicted by our model.

\footnotetext{
${ }^{9}$ Another possibility is that private bank note issue can provide a kind of liquidity that is welfare improving even when other currency is not scarce. The study of this possibility, however, is beyond the scope of this paper.
} 


\section{A. Welfare}

One important property of our model, which was particularly useful in our existence argument of the previous section, is that as the discount factor increases and so does the reward for future consumption, nonbanks will agree to accept money as long as money remains relatively scarce. That scarcity is assured by the conservative issue induced by the high profitability of the banking sector, that is, by $\beta$ being sufficiently high. The above argument also holds true in cases where creation of government currency is arbitrarily small. This allows us to conclude that for $\beta$ sufficiently high, a monetary steady state with banking exists even if $\mu_{c}=0$. In such a steady state, with only private notes and no government money, there is positive consumption, and all expected discounted utilities are positive. If, however, banks are prohibited from issuing notes, the only steady state that is attained when government currency is in zero supply is autarky with zero utilities. The same argument holds if government currency exists but is extremely scarce. These remarks amount to the following.

Proposition 3. If government currency is sufficiently scarce ( $\mu_{c}$ is sufficiently close to zero), then welfare in a monetary steady state with banking is strictly higher than that attained by a steady state in which banks are prohibited from issuing notes.

\section{B. Some Historic Episodes}

There have been several examples of private monetary systems in recent history. England, Scotland, and the United States, among other countries, experienced partially private monetary systems in the eighteenth and nineteenth centuries. England allowed for note-issuing country banks. These small banks were notoriously unstable, perhaps as a consequence of 
regulations limiting their size to no more than six partners. Unlike the English system, overissue was not a problem in the Scottish system, where no partnership restrictions existed. The banks accepted each other's notes and evolved a system of note exchange. In addition, the circulation of small notes was often viewed as a natural response to external drains of coins (see Hanson 1979; White 1984) . The evidence is mixed regarding the effects of note-issue privileges on the stability of banking in the United States ( see Rolnick and Weber 1984).

Unlike our model, a previous literature has related banking stability to quality competition and marginal costs of note circulation (see Klein 1974; White 1984). Costs could arise from real investments that ensure public confidence in the reliability of the issuer. However, to appeal to quality competition is problematic in some contexts. For instance, studies of the National Banking Era, prior to the establishment of the Federal Reserve system in the United States, indicate that the public was largely indifferent between holding bank notes and lawful money. Champ, Wallace, and Weber (1994) have argued that national banks were never close to issuing notes up to the limit that the law would permit. They conjecture that this behavior was due to a concern on the part of banks about notes not staying in circulation long enough. Our model provides a rationale for their view and shows that quality competition may not be necessary for banking stability. 


\section{Appendix}

Here we formally describe the mapping $T_{\alpha, \gamma, \phi}$ governing the law of motion of $(\mathbf{x}, \mathbf{y}, z)$. For states such that $\sum_{r, m} x_{r, m}+y_{0}+y_{1}=\frac{1}{k}$, the above mapping is given by the right side of the equations below, together with the expressions from the steady state definition relating $p, q$, $d$, and $\pi$ to $(\alpha, \gamma, \phi)$. For nonbanks, we have

$$
y_{1}=(1-\delta)\left(y_{1}+q y_{0}-p y_{1}\right)+\frac{1}{k}\left(z+\delta \mu_{c}\right)
$$

and

$$
y_{0}=(1-\delta)\left(y_{0}-q y_{0}+p y_{1}\right)+\frac{\delta}{k}\left(1-\mu_{c}-\mu_{b}\right) .
$$

For banks, we have

$$
\begin{aligned}
z= & k\left\{\sum_{m \geq 1} \sum_{r=0}^{m-1} \sum_{i=r+1}^{m}\left(\begin{array}{c}
m \\
i
\end{array}\right) \pi^{i}(1-\pi)^{m-i} x_{r, m}+\right. \\
& \sum_{m \geq 0} \sum_{r=0}^{m}(1-d) x_{r, m} \phi_{r, m}\left(\begin{array}{c}
m \\
r
\end{array}\right) \pi^{r}(1-\pi)^{m-r} \\
& \left.-\sum_{m \geq 1} \sum_{r=0}^{m} \gamma_{r, m}\left(\begin{array}{c}
m \\
r+1
\end{array}\right) \pi^{r+1}(1-\pi)^{m-(r+1)} x_{r, m}\right\}
\end{aligned}
$$

and

$$
\begin{aligned}
x_{r^{\prime}, m^{\prime}}= & (1-\delta) \sum_{m \geq m^{\prime}}\left(\begin{array}{c}
m \\
m-m^{\prime}
\end{array}\right) \pi^{m-m^{\prime}}(1-\pi)^{m^{\prime}}\left\{q \gamma_{r^{\prime}+m-m^{\prime}-1, m^{\prime}} x_{r^{\prime}+m-m^{\prime}-1, m}+\right. \\
& q\left(1-\gamma_{r^{\prime}+m-m^{\prime}, m}\right) x_{r^{\prime}+m-m^{\prime}, m}+p d \phi_{r^{\prime}+m-m^{\prime}, m-1} x_{r^{\prime}+m-m^{\prime}, m-1}+ \\
& p(1-d) \phi_{r^{\prime}+m-m^{\prime}+1, m} x_{r^{\prime}+m-m^{\prime}+1, m}+p\left(1-\phi_{r^{\prime}+m-m^{\prime}, m}\right) x_{r^{\prime}+m-m^{\prime}, m} \\
& \left.\left(\frac{1}{k}-p-q\right) x_{r^{\prime}+m-m^{\prime}, m}\right\}+I_{r^{\prime}, m^{\prime}} \frac{\delta+z}{k}
\end{aligned}
$$


for all $r^{\prime}, m^{\prime} \geq 0$, where $I_{r^{\prime}, m^{\prime}}$ is an indicator function that assumes value 1 if $\left(r^{\prime}, m^{\prime}\right)=$ $(0,0)$, and value 0 otherwise. 


\section{References}

Aiyagari, S. Rao, and Wallace, Neil. "Existence of Steady States with

Positive Consumption in the Kiyotaki-Wright Model." Review of Economic

Studies 58 (October 1991): 901-16.

Arrow, Kenneth; Karlin, Samuel ; and Scarf, Herbert. Studies in the

Mathematical Theory of Inventory and Production. Stanford : Stanford

University Press, 1958.

Champ, Bruce; Wallace, Neil; and Weber, Warren E. "Interest

RatesUnder the U.S. National Banking System." Journal of Monetary

Economics 34 (December 1994): 343-58.

Edgeworth, Francis Y. "The Mathematical Theory of Banking." Journal of the Royal Statistical Society 51 (March 1888): 113-27.

Fischer, Stanley. "Friedman Versus Hayek on Private Money:

Review Essay." Journal of Monetary Economics 17 (May 1986): 433-39.

Friedman, Milton. A Program for Monetary Stability. New

York: Fordham University Press, 1959.

Hanson, John R. II. "Money in the Colonial American Economy: An Extension." Economic Inquiry 17 (April 1979): 281-86.

Holmström, Bengt, and Tirole, Jean. "Private and Public Supply of Liquidity." Journal of Political Economy 106 (February 1998): 1-40.

Kiyotaki, Nobuhiro and Wright, Randall (1989). "On Money as a Medium of Exchange". Journal of Political Economy 97 (August 1989): 927-54. 
Klein, Benjamin. "The Competitive Supply of Money." Journal of Money, Credit and Banking 6 (November 1974): 423-54.

Orr, Daniel., and Mellon, W. G. "Stochastic Reserve Losses and Expansion of Bank Credit." American Economic Review 51 (September 1961): $614-623$.

Phillips, Chester A. Bank Credit: A Study of the Principles and Factors Underlying Advances Made by Banks to Borrowers. New York: The Macmillan Company, 1920.

Rolnick, Arthur J., and Weber, Warren E. "The Causes of Free Bank Failures: A Detailed Examination." Journal of Monetary Economics 14 (November 1984): 267-91.

Schwartz, Anna J. "Banking School, Currency School, Free Banking School." In The New Palgrave: A Dictionary of Money and Finance, edited by P. Newman,M. Milgate, and J. Eatwell. 1st ed. London: MacMillan Press Limited, 1987.

Sargent, Thomas. J., and Wallace, Neil. "The Real-Bills Doctrine versus the Quantity theory: A Reconsideration." Journal of Political Economy 90 (December 1982): 1212-36.

Tobin, James. "An Essay on the Principles of Debt Management." In $\underline{\text { Commission on Money and Credit, Fiscal and Debt Management Policies, }}$ edited by Englewood Cliffs. N.J.: Prentice-Hall, 1963.

White, Lawrence H. Free Banking in Britain: Theory, Experience, and Debate, 1800-1845. Cambridge: Cambridge University Press, 1984. 